\begin{tabular}{|c|c|c|c|c|c|c|}
\hline \multirow{4}{*}{ Impact Factor: } & ISRA (India) & $=3.117$ & SIS (USA) & $=0.912$ & ICV (Poland) & $=6.630$ \\
\hline & ISI (Dubai, UAE & $=0.829$ & РИНЦ (Russia & $=0.156$ & PIF (India) & $=1.940$ \\
\hline & GIF (Australia) & $=0.564$ & ESJI (KZ) & $=\mathbf{5 . 0 1 5}$ & IBI (India) & $=4.260$ \\
\hline & JIF & $=1.500$ & SJIF (Morocco & $=5.667$ & OAJI (USA) & $=0.350$ \\
\hline
\end{tabular}

\begin{tabular}{|c|c|}
\hline $\begin{array}{l}\text { SOI: } 1.1 / 7 \\
\text { International S } \\
\text { Theoretical } \mathbb{\&}\end{array}$ & $\begin{array}{l}\frac{\text { AS }}{\text { DOI: } 10.15863 / \mathrm{TAS}} \\
\text { cientific Journal } \\
\text { Applied Science }\end{array}$ \\
\hline p-ISSN: 2308-4944 (print) & e-ISSN: 2409-0085 (online) \\
\hline Year: $2019 \quad$ Issue: 01 & Volume: 69 \\
\hline Published: 30.01 .2019 & http://T-Science.org \\
\hline
\end{tabular}

SECTION 32. Jurisprudence.
QR - Issue

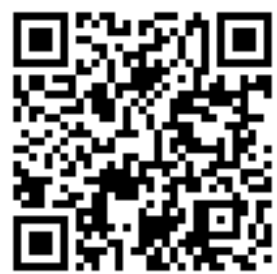

Adilbek Kachkinbekovich Biybosunov head of the Academy of the Ministry of Internal Affairs of the Kyrgyz Republic, Candidate of Juridical Sciences

\title{
QUESTIONS OF CONTROL AND SUPERVISION RELATIONS IN THE LEGAL SYSTEM OF THE KYRGYZ REPUBLIC
}

Abstract: So far, the concepts of "control" and supervision are used as identical concepts, although there are significant differences in their legal nature, which creates certain difficulties and conflict points in the exercise of their powers by state bodies. The article deals with the relationship of control and supervision. Their similarities and differences.

Key words: control, supervision, correlation of the concepts of inspection and supervision, conflict points, significant differences.

Language: Russian

Citation: Biybosunov, A. K. (2019). Questions of control and supervision relations in the legal system of the Kyrgyz republic. ISJ Theoretical \& Applied Science, 01 (69), 284-286.

Soi: http://s-o-i.org/1.1/TAS-01-69-39 Doi: crossef https://dx.doi.org/10.15863/TAS.2019.01.69.39

\section{ВОПРОСЫ СООТНОШЕНИЯ КОНТРОЛЯ И НАДЗОРА В ПРАВОВОЙ СИСТЕМЕ КЫРГЫЗСКОЙ РЕСПУБЛИКИ}

Аннотация: до настоящего времени, понятия «контроль» и надзор» используются как идентичные понятия, хотя есть существенные различия в их правовой природе, что создает определенные трудности и коллизионные моменты в осуществлении своих полномочий государственными органами. В статье рассмотрены вопросы соотношения контроля и надзора. Их сходства и различия.

Ключевые слова: контроль, надзор, соотночение понятий проверки и надзора, коллизионные моменты, существенные различия.

\section{Introduction}

В современной юридической науке, понятия «контроль и надзор» используются как смежные понятия, так как нет до сих пор единого определения данным понятиям, что создает определенные сложности в определении полномочий государственных органов. В системе государственного правления, контроль и надзор и проверка являются инструментами государственного воздействия на регулирование определенных правовых отношений. Но именно схожесть в понятиях, создает множество коллизионных моментов и требует глубокого теоретического анализа с целью разграничения их.

\section{Materials and Methods}

В теории законодательной практики, данные понятия также используются нередко и довольно часто как равнозначные. К примеру, Закон
Кыргызской Республики «О прокуратуре Кыргызской Республики», Закон КР «Об уполномоченном государственном органе в сфере надзора и регулирования финансового рынка»[1].

Если обратиться к словарю Ожегова С.И., то понятие «контроль» понимается как «проверка, а также постоянное наблюдение в целях проверки или надзора»[2].

Учитывая, что и в Словаре Ожегова С.И. данные понятия не разграничены, а даны в совокупности, правоведы начали предлагать свое собственное видение по данным понятиям. Так, Гуляев А.П., например, контроль рассматривает как составную часть управления, цель которой обеспечить наиболее эффективную, результативную, целесообразную деятельность для лучшего достижения поставленных целей и задач. [3, с. 9]. 


\begin{tabular}{|c|c|c|c|c|c|c|}
\hline \multirow{4}{*}{ Impact Factor: } & ISRA (India) & $=3.117$ & SIS (USA) & $=0.912$ & ICV (Poland) & $=6.630$ \\
\hline & ISI (Dubai, UAE & $=0.829$ & РИНЦ (Russia) & $=0.156$ & PIF (India) & $=1.940$ \\
\hline & GIF (Australia) & $=0.564$ & ESJI (KZ) & $=5.015$ & IBI (India) & $=4.260$ \\
\hline & JIF & $=1.500$ & SJIF (Morocco) & $=5.667$ & OAJI (USA) & $=0.350$ \\
\hline
\end{tabular}

«Контроль, - отмечает В.Г. Афанасьев, - это труд по наблюдению и проверке соответствия процесса функционирования объекта принятым управленческим решениям, законам, планам, нормам, стандартам, правилам, приказам и т.д.; выявлению результатов воздействия субъекта на объект, допущенных отклонений от требований управленческих решений, от принятых принципов организации и регулирования» $[4$, с. 125].

В.П. Беляев определяет контроль как форму юридической деятельности, при которой управомоченные органы и лица в рамках контрольного производства для получения юридически значимых результатов и оказания (обеспечения) регулирующего воздействия осуществляют на подконтрольных объектах сбор и проверку информации о фактическом выполнении нормативных предписаний, соблюдении требований нормативных и правовых актов и непосредственно принимают меры по предупреждению и пресечению допущенных нарушений (отклонений) в целях обеспечения охраны интересов общества и государства, защиты прав и свобод граждан $[5, \mathrm{c}$. 25].

Следует отметить, что контроль и надзор представляют собой вид юридической ответственности.

Отличительным признаком контроля является его властный характер, то есть для выполнения государственно-властных полномочий, то есть каждый гражданин наделенный право контроля за каким либо объектом, в целях предотвращения и пресечения правонарушений [10].

Понятие «надзор» в Кыргызской Республике ассоциируется, прежде всего, прокурорским надзором, что достаточно раскрыто в Конституции Кыргызской Республики, а именно в ст. 104 Конституции, где сказано, что «Прокуратура составляет единую систему, на которую возлагается:

1) надзор за точным и единообразным исполнением законов органами исполнительной власти, а также другими государственными органами, перечень которых определяется конституционным законом, органами местного самоуправления и должностными лицами указанных органов»[6]. Кроме этого, в Законе КР «О прокуратуре КР», в ст. 3 Закона, сказано, что «в целях обеспечения верховенства закона, единства и укрепления законности, а также охраняемых законом интересов общества и государства прокуратура Кыргызской Республики осуществляет:

-надзор за точным и единообразным исполнением законов органами исполнительной власти, органами местного самоуправления, их должностными лицами $[7,8]$.

Воздействие права на общественные отношения, возникающие в управлении, осуществляется через множество стадий, на которых реализуются нормы права, возникают соответствующие правоотношения, выражающиеся в существовании прав и обязанностей у управляющих и управляемых. Осуществление правового контроля возможно при наличии правового воздействия на управление, так как только в этом случае достигается упорядоченность управленческих отношений, устанавливается правопорядок, реализуется принцип законности.

Сам механизм действия права в управлении приобретает управленческий аспект, проявляющийся, в том числе и во влиянии на правовой контроль, следующим образом: 1) правовой механизм, включающий в себя правовой контроль, является специфической формой управленческого воздействия на общественные отношения; 2) право непосредственно воздействует на элементы управления, в том числе и на правовой контроль.

Юридической науке предстоит еще многое сделать в области совершенствования правового контроля. Однако выверить и оценить конечную эффективность влияния права на управление, в том числе, с помощью правового контроля, призвана наука управления. Методологически при этом обнаруживается органическое единство организационного и правового подходов, с одной стороны, а с другой - связь и зависимость юридической науки и науки управления, их взаимодействие.

Таким образом, при дальнейшем изучении правового контроля как подфункции контрольной функции управления, осуществляемого в любой организационной системе, должны учитываться вышеуказанные положения [11].

Соотношение понятий контроля и надзора остается актуальным вопросом современной юриспруденции. Проведя анализ вышеуказанных понятий, можно сделать следующие выводы:

К схожим признакам контроля и надзора относятся:

- цель контрольной и надзорной деятельности - обеспечение соблюдения и защиты прав и свобод человека и гражданина;

- принцип гласности в осуществлении;

- методы осуществления - проверки, ревизии, мониторинг и т.д.

К отличительным признакам относятся:

- распространение контроля на более широкий круг правоотношений подконтрольных объектов; 


\begin{tabular}{|c|c|c|c|c|c|c|}
\hline \multirow{4}{*}{ Impact Factor: } & ISRA (India) & $=3.117$ & SIS (USA) & $=0.912$ & ICV (Poland) & $=6.630$ \\
\hline & ISI (Dubai, UAE & $=0.829$ & РИНЦ (Russia) & $=0.156$ & PIF (India) & $=1.940$ \\
\hline & GIF (Australia) & $=0.564$ & ESJI (KZ) & $=\mathbf{5 . 0 1 5}$ & IBI (India) & $=4.260$ \\
\hline & JIF & $=1.500$ & SJIF (Morocco) & $=5.667$ & OAJI (USA) & $=0.350$ \\
\hline
\end{tabular}

- проведение контроля только в отношении организационно подчиненных объектов, надзора - в отношении неподчиненных объектов;

- применение мер воздействия при контроле носит дисциплинарный характер, а при надзоре административный, уголовный;

- вмешательство в текущую административно-хозяйственную деятельность объекта при надзоре не допускается, при контроле - допускается [9].

\section{Conclusion}

Сравнивая контроль и надзор можно сделать заключение о том, что понятие «контроль» шире понятия «надзор», равно как контролирующие органы обладают более широким кругом полномочий при осуществлении своей деятельности, чем надзорные.

\section{References:}

1. (2009). Zakon $K R \ll O b$ upolnomochennom gosudarstvennom organe $v$ sfere nadzora $i$ regulirovaniya finansovogo ryinka» ot 24 iyulya 2009 goda \#249.

2. Ozhegov, S. I. (1992). Tolkovyiy slovar russkogo yazyika sovmestno s N.Yu. Shvedovoy.

3. Gulyaev, A. P. (1999). Kontrolnyie organyi $i$ organizatsii Rossii. Moscow.

4. Afanasev, V. G. (1977). Chelovek v upravlenii obschestvom. (p.382). Moscow.

5. Belyaev, V. P. (2006). Kontrol i nadzor kak formyi yuridicheskoy deyatelnosti: voprosyi teorii i praktiki: dis. ... d-ra yurid. nauk. (p.436). Saratov.

6. (2016). Konstitutsiya Kyirgyizskoy Respubliki ot 28.12. 2016 goda.

7. (n.d.). Zakon o prokurature Kyirgyizskoy Respubliki ot 17 iyulya 2000 goda \#224 (s izmeneniyami ot 5 marta 2016 goda \#19).
8. Amanzholova, B. A. (2008). Teoreticheskie $i$ metodologicheskie aspektyi formirovaniya sistem vnutrennego kontrolya vzaimosvyazannyih organizatsiy. Uchebnoe posobie. (p.260). Novosibirsk: Novosib. gos. un-t.

9. Bonner, A. T. (1992). Zakonnost i spravedlivost $v$ pravoprimenitelnoy deyatelnosti. (p.320). Moscow: Rossiyskoe pravo.

10. Butyilin, V. N., Goncharov, I. V., \& Barbin, V. V. (2007). Obespechenie prav $i$ svobod cheloveka $i$ grazhdanina $v$ deyatelnosti organov vnutrennih del (organizatsionno-pravovyie aspektyi): Kurs lektsiy. (p.254). Moscow: Akademiya upravleniya.

11. Cluchevskaya, Y. A. (2010). Organizatsiya $i$ osuschestvlenie pravovogo kontrolya $v$ sisteme upravleniya organami vnutrennih del. Dissertatsiya na soiskanie kandidata yuridicheskih nauk. (p.259). Moscow. 